\title{
Effect of Initial Carbon Sources on the Performance of a Microbial Fuel Cell Containing Environmental Microorganism Micrococcus luteus
}

\author{
Youngiin Choi, Eunkyoung Jung, Hyunjoo Park, Seunho Jung, and Sunghyun Kim \\ Department of Bioscience and Biotechnologv, Konkuk Lniversity, Seoul 143-701, Korea \\ ${ }^{*}$ E-mail: shingakonkukac.kr; skimlooa konkukac.kr \\ Received April 26, 2007
}

Key Words : Microbial fiel cell. Initial culture conditions. Micrococcus luteus

A microbial fuel cell (MFC) is a device that uses microorganisms as a catalyst for the direct conversion from chemical energy to electrical energy without intental combustion steps. ${ }^{1.5}$ Environmental friendliness and high efficiency have projected an MFC as one of the promising and alternative future energy sources. The fact that there is a large selection of microorganisms and substrates offers additional advantages over conventional fuel cells in that various types of MFCs could be devised, meeting the specific envirommental requirements. There are reports that direct energy production is possible even from marine sediments using geobacters. ${ }^{6,7}$

In an MFC, electrons are initially trapped as a form of reduced intermediates following the degradation of substrate and transferred to the anode. Microorganisms as well as redox mediators thus constitute an essential part of the microbial fuel cell, in that a large improvenent in a fuel cell operation could be achieved by selecting suitable catalytic bacteria. It is notable that mediator-less MFCs have been developed using Shewrmella putrefaciens in which cytochromes located in the outer membrane are responsible for the direct electron transfer to the anode. Also notable is the MFC that utilizes even light energy by Anabaena variabilis or Sinechococcus sp. ${ }^{8.9}$

It is our ongoing effort to develop a high performance MFC in which a maximum utilization of substrates and high power density can be achieved. In the previous research. we have shown that the MFC perfornance quite depends on the various operating factors such as temperature. choice of mediators. concentration of substrates and mediators, and environmental shock. Also found was that carbon sources crucially affected performance. ${ }^{10.14}$

This paper describes the preliminary study of the microbial fuel cells using Micrococcus hitens, ${ }^{15}$ a typical environmental microorganism, which is found in soil, dust. water, and air. It is known to tolerate high salt concentration. This halophilic nature can make this bacterium a promising candidate for a MFC. We have carried out a sy stematic study of the effect of initial culture conditions on the MFC performance using a variety of carbohydrates as an initial substrate and a fuel to see whether this bacterium could be used as an effective biocatalyst in MFCs. Although the fuel cell efficiency was not as high as when more conmon bacteria such as Proteus vulgaris and Escherichia coli were used, the results showed Micrococcts hitets is a promising environmental microorganisms from which a MFC could be constructed.

\section{Experimental Section}

Preparation of microorganisms. Micrococcus litets ( $\mathrm{KCCM} 40166$, IFO 3066) was purchased from the Korean Culture Center of Microorganisms (KCCM) and kept on a nutrient agar plate at $4{ }^{\circ} \mathrm{C}$. Experimental cultures were grown at $30^{\circ} \mathrm{C}$ in a nutrient broth containing $10 \mathrm{~g}$ of polypeptone. $2 \mathrm{~g}$ of yeast extract. and $\mathrm{I} \mathrm{g}$ of $\mathrm{MgSO}_{4}$ per liter of distilled water. (pH 7). To test initial carbon source effects on the fuel cell efficiency, the bacteria were cultured in the medium that contained $10 \mathrm{~g}$ of polypeptone and $5 \mathrm{~g}$ of a carbon source per liter. Total 11 carbon sources (yeast extract. galactose. glucose, lactose. maltose. manuitol, mannose, sorbitol, fructose. sucrose, and starch) were used as an initial carbon source and each was added to the medium after sterilization. The same carbon sources except yeast extract were utilized as a substrate during the fuel cell operation. Each culture containing a carbon source was daily sub-cultured with $5 \%$ inoculums for three days. Cells were harvested by centrifugation at $3,000 \times \mathrm{g}$ for $10 \mathrm{~min}$ at their early stationary phase and washed three times with $0.05 \mathrm{M}$ phosphate buffer of $\mathrm{pH} 7$ at $4{ }^{\circ} \mathrm{C}$. The washed microorganisms were resuspended in the buffer to give $20 \mathrm{mg}$ (dry weight) per $\mathrm{mL}$ for the following experiments.

Fuel cell assembly. A prototype fuel cell was constructed according to the previous design. ${ }^{11}$ Each cell unit is composed of anode and cathode compartments (internal dimensions $45 \times 45 \times 15 \mathrm{~mm}$ ) and separated by a cation exchange membrane (Nafion 117. Aldrich, USA). A reticulated vitreous carbon (RVC, $30 \times 30 \times 12 \mathrm{~mm}, 80$ pores per inch, E-tek, USA) plate was used as an anode. RVC has a physical structure that can allow easy access of organisms and mediators to the electrode surface through the open network and provide a high surface area for the reaction. Anolyte and catholyte were composed of $0.05 \mathrm{M}$ phosphate buffer and $0.1 \mathrm{M}$ ferricyanide solutions, respectively. Microorganism and mediators were added to the anodic compartment. 10 $\mu \mathrm{mol}$ and $5 \mu \mathrm{mol}$ of mono- and disaccharides were added to the anolyte as a substrate, respectively. so that the same number of electrons could be produced when completely 
oxidized. For starch, the amount was adjusted to give 10 $\mu$ mol glucose units. A platinum plate $(30 \times 30 \times 0.2 \mathrm{~mm})$ was used as a cathode. Fach compartment was sealed by 1.5 mın-thick silicon rubber gaskets, and held in a frame that was tightly bolted together. During the experiments, nitrogen flowed through the cell compartments to keep oxygen from entering the cell and for effective mixing of the solution. Operation temperature was Inaintained constant in a water bath.

Electrical measurements. The discharging curve was recorded only after the open circuit voltage was stabilized with nitrogen gas flowing through the cell. Discharge was done by connecting an external load $(560 \Omega)$ between the anode and the cathode to obtain a polarization curve. The cell voltage with time was then recorded with a personal computer equipped with an analog-to-digital board (Computer Boards, Mansfield, MA, USA). Current was calculated by using the Ohm's law, $\mathrm{l}=\mathrm{V}_{\mathrm{cell}} / \mathrm{R}_{\text {lousd }}$. When the cell voltage dropped to the background level, the cell was charged with a carbon source for another measurement. Generally, the cell voltage increases rapidly upon injection of carbohydrates and reaches a plateau level as long as there are enough carbohydrates to be consumed by microorganisms, and then the cell voltage begins to gradually decrease. Actually produced electricity can be calculated by integrating the discharge curve with time, $Q=\int 1(t) d t$. For the complete oxidation of glucose, the anodic reaction is given by

$$
\mathrm{C}_{6} \mathrm{H}_{12} \mathrm{O}_{6}+6 \mathrm{H}_{2} \mathrm{O} \rightarrow 6 \mathrm{CO}_{2}+24 \mathrm{H}+24 \mathrm{e}^{-}
$$

24 electrons should be generated from one molecule of glucose in an ideal condition. The coulombic efficiency was then calculated as the ratio of the output charge obtained from the fuel cell to the theoretical maximum coulombic equivalent of $24 \times 96.485 \mathrm{C} \cdot \mathrm{mol}^{1}$ of added monosaccharides. In the same way, efficiency was calculated for diand polysaccharides.

\section{Results and Discussion}

The effect of three different kinds of mediators on the fuel cell performance was tested with glucose as a fuel (Fig. 1): Thionin, 2-hydroxy-1.4-naphthoquinone (HNQ), and methyl orange belong to phenothiazine, quinone, and azo family and are commonly used as an electron shuttle to the anode. Although safranine $O$ (phenazine) was also tested, it generated virtually no current output. Thionin was found to give the best result. showing the highest current for the longest time. It is ascribed to the fact that electron transfer from $\mathrm{NADH}$ to thionin is more rapid than HNQ. ${ }^{16}$ Thionin was also found rather freely penetrate the cell membrane from our previous study. ${ }^{17}$ We also changed the concentration of glucose as a carbon source and found $50 \mathrm{mM}$ concentration gave the most reproducible and better results than at any other concentrations. Therefore, we used thionin as a redox mediator and fixed glucose concentratin at $50 \mathrm{mM}$ throughout the experiments.

rigure 2 (panels A to I) shows a series of discharging

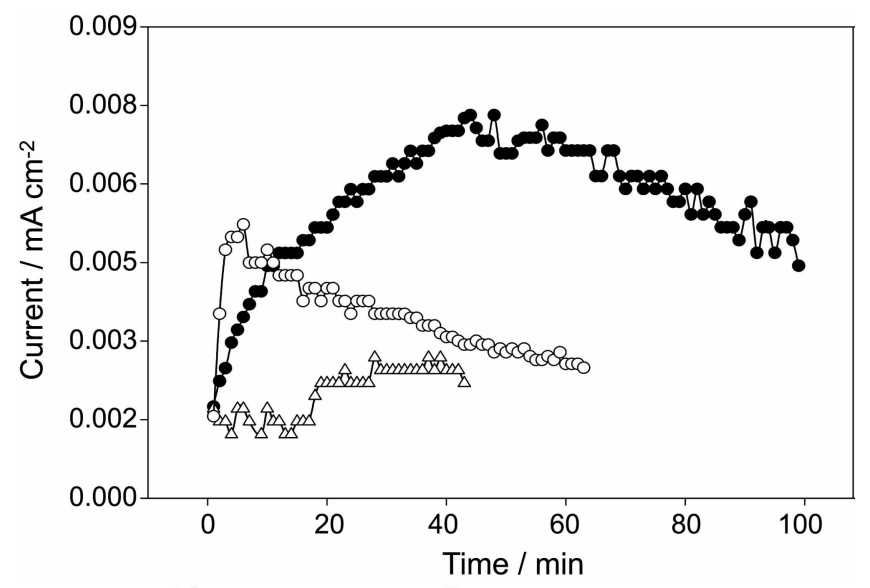

Figure 1. Effect of the redox mediators on the performance of a MFC containing Hiforococus lttetus. Yeast extract was used as an initial carbon source. Mediators are thionin (O), 2-hydroxy-1.4naphthoquinone ( $O$ ) and methyl orange $(A)$.

curves with time when different carbon sources were used in an initial culture medium. The cell was fully discharged before each carbon source was added. Initially used carbon sources were yeast extract, glucose, galactose, lactose, mannitol, mannose, sorbitol, starch, and sucrose. fructose and also the same number of carbon sources were used as substrates. Among these, sucrose and fructose did not give any significant current output regardless of initial culture conditions. Here we denote Glu-ini, for example, to describe the condition where glucose was initially added to culture as a carbon source. Likewise, Yea-ini, Gal-ini, Lac-ini, Mai-ini, Man-ini. Sor-ini, and Sta-ini mean that Yeast extract, galactose, lactose, mannitol, mannose, sorbitol, and starch were used initially as a carbon source, respectively. Table 1 sumınarizes coulombic efficiency for various initial carbon conditions and substrates.

Most noticeable is when yeast extract was used as an initial carbon source (panel A) in which the highest output current and longer current duration was resulted with the injection of glucose and starch. When mannose was added. output current was relatively lower than those of glucose and starch, but it lasted longer. However, with galactose injection, the initial high current rapidly decreased. Maltose, sorbitol, and sucrose were not significantly utilized with Yea-ini condition.

Panel B shows output current pattern with Glu-ini when various carbon sources were used. Starch gave the highest coulombic efficiency and showed a stable output current pattern. Glucose also gave somewhat high output current and coulombic efficiency. In the mean time, lactose, galactose, maltose, and mannose did not show significant current output. Other carbon sources showed no or negligible current output.

When starch was used as an initial carbon source (panel C), starch was mostly utilized, giving highest current and longer current duration. Glucose was also well utilized. Interestingly, only sorbitol among other tested carbohydrates was utilized. However, starch as a carbon source was not 

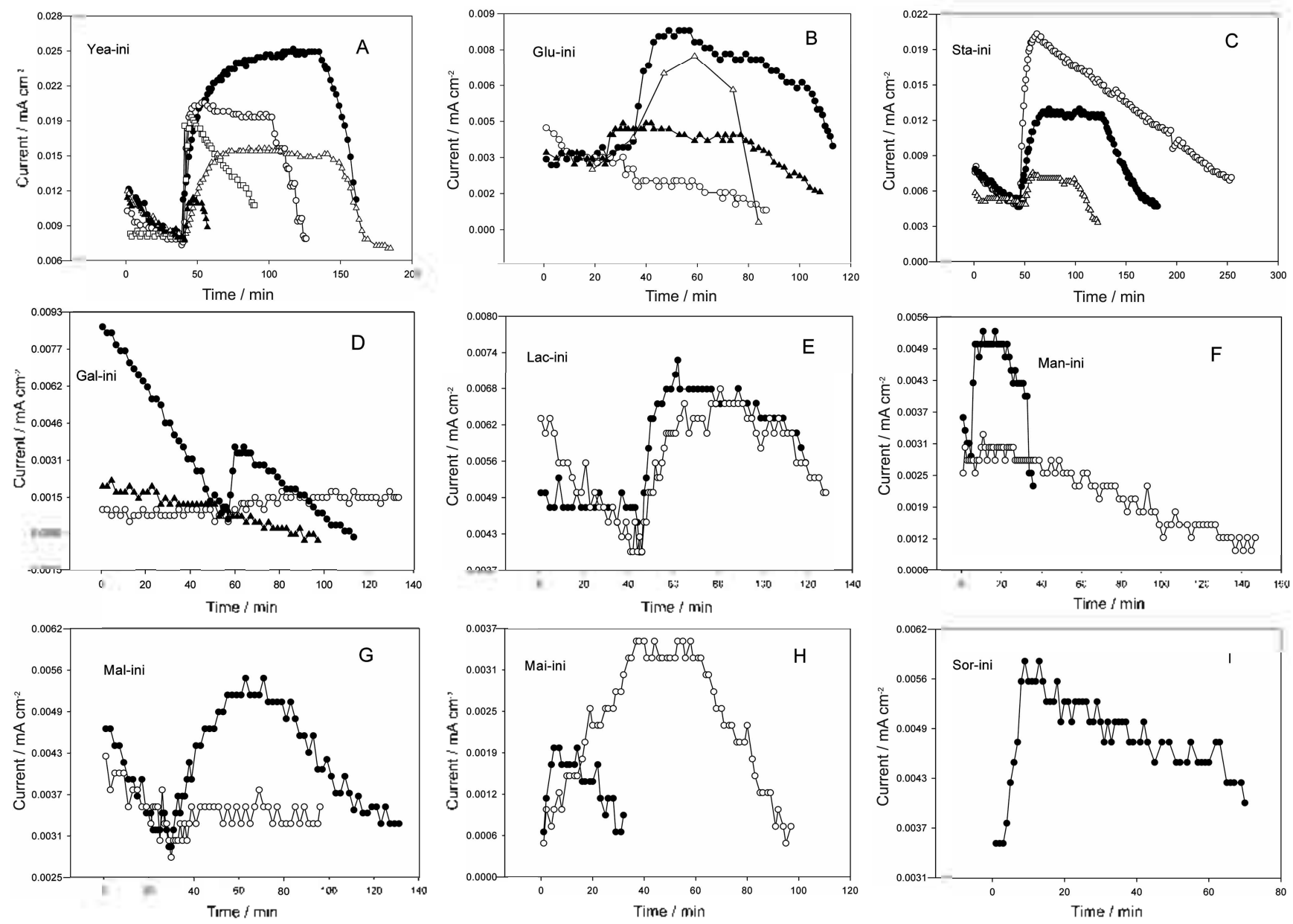

Figure 2. Vartation of curent oulput with time for diferent carbon sources in a luel cell containing wicrococcus latens cultured under

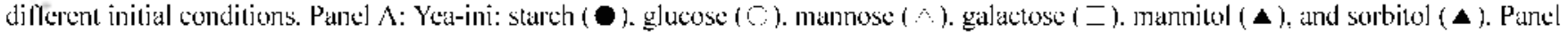
B: Glu-ini: starch ( ). glucose (A). A represents lactose, galactose, maltose. and mannose. - represents other carbon sources. Panel C: Sta-ini: starch (C). glucose ( $)$ ). and lactose ( $A$ ). Panel D: Gal-ini: starch (C). glucose ( 4 ), and mannose ( $\bullet$ ). Panel F: l ac-inj: glucose (C) and starch (๑). Panel I\% Man-ini: glucose (O) and mannose (C). Panel Gi: Mal-ini: starch (O) and maltose (C). Panel II: Mai-ini; glucose (O) and mannitol (C). Pancl I: Sor-ini; glucose (O). Added mono- and disaccharides were 10 , amol and 5 pmol. respectively. Apparent surface area of the anode was $32.4 \mathrm{~cm}^{2}$.

utilized when sorbitol was used in an initial culture medium. In the case of Gal-ini condition (panel D), mannose was mostly effectively utilized. Starch showed a low but stable current output pattern. Other carbohydrates did not show any current output. Thus, Gal-ini condition may be avoided for an effective fuel cell operation.

Panels $E$ through I are current output patterns when lactose, mannose, maltose, mannitol, and sorbitol were used in an initial culture medium, respectively. With Lac-ini (panel E), only starch and glucose gave rise to small current output lasting for a short period. Surprisingly, even lactose did not show any current output although bacteria were initially conditioned with the same carbon source. Lactose itself is one of the very ineffective carbon sources. For Malini condition, only starch and maltose gave some current output (panel F). Likewise, mannose and mannitol were effectively utilized when the same compounds were used in an initial culture medium (panels $\mathrm{G}$ and $\mathrm{H}$ ). In both cases. glucose also showed current output. In the case of Sor-ini, glucose was the only one to be utilized (panel I). As in the
Lac-ini case, even sorbitol was not utilized.

From these experiments, the following facts could be deduced. First, it is generally true that carbon sources are well utilized when the same carbon sources are used in initial culture media. This is ascribed to the fact that the metabolic pathway in microorganisms is already adapted by the same carbon sources. Among monosaccharides, glucose is mostly utilized regardless of initial conditions. The same phenomenon was observed in some extremophiles such as Bacillus licheniformis and Bacillus themoglucosidasius. thermophilic microorganisıns. Disaccharides are generally not utilized. The fact that almost no current output was resulted when fructose was used either as an initial carbon source or as a substrate indicates that pentose is not utilized as well as hexose. This explains why no measurable current was observed with sucrose, which has a pentose unit. It is rather surprising that starch gave very high current outputs.

The fact that the current output pattern changed dramatically when their initial culture condition was altered by various carbon sources implies that the fuel cell performance 
Table 1. Coulombic Efticiency (\%) for Various Carbon Source Conditions in the Microbial Fuel Cell Containing ificrococctus hutetus

\begin{tabular}{|c|c|c|c|c|c|c|c|c|}
\hline \multirow{2}{*}{$\begin{array}{l}\text { Initial Carbon } \\
\text { Source }\end{array}$} & \multicolumn{8}{|c|}{ Utilized Carbon Sources } \\
\hline & Glucose & Lactose & Maltose & Mannose & Mannitol & Sorbitol & Galactose & Starch \\
\hline Yeast extract & 4.6 & - & - & 3.6 & 0.3 & 0.3 & 1.9 & 14.5 \\
\hline Glucose & 1.4 & 0.6 & 0.6 & 0.6 & 0.1 & 0.1 & 0.6 & 1.6 \\
\hline Starch & 3.3 & 1.3 & - & - & - & 0.6 & - & 9.6 \\
\hline Galactose & 0.1 & - & - & 0.5 & - & - & - & 0.7 \\
\hline Lactose & 0.5 & - & - & - & - & - & - & 0.5 \\
\hline Mannose & 0.6 & - & - & 0.6 & - & - & - & - \\
\hline Maltose & - & - & 0.2 & - & - & - & - & 1.2 \\
\hline Manuitol & 0.3 & - & - & - & 1.6 & - & - & - \\
\hline Sorbitol & 0.5 & - & - & - & - & - & - & - \\
\hline
\end{tabular}

Current output was not observed when the bacterial fuel cells were operated with fructose, sucrose as utilized carbon sources

could be easily manipulated by simply changing culture conditions and/or substrates.

In summary, a fundamental study for the microbial fuel cells containing Micrococctis hiteus. an environmental microorganism, was performed in order to achieve the optinal efficiency of the fuel cell operation. The fuel cell performance was highly dependent on the choice of a mediator and initial culture conditions and the kind of substrates. Glucose could be the general substrate regardless of initial carbon sources. Starch turned out to be one of the promising carbon sources. This work showed possibility to use envirommental nicroorganisnis as a catalyst in MFCs. Further investigation with different environmental microorganisms under various operating conditions is in the progress.

Acknowledgement. This work was supported by Korea Research Foundation Grant (KRF 2005-070-C00084) SK expresses his thank to Konkuk University for the funancial support during his sabbatical year.

\section{References}

1. Turner. A. P. F.: Aston, W. I.: Higgins. I. I.: Davis, G.: Hill, H. A. O. Biotechlol Biong. Symp. 1982. 12. 401.

2. Lovley. D. R. Cur Opinion Biotechnol. 2006. 17. 327.
3. Rabaey. K: Verstraete. W. Trend Biotechnol. 2005. 23. 291.

4. Logan. B.: Hamelers. B.: Rozendal. R.: Schroder. U.: Keller. J.: Freguia, S.: Aelterman. P.: Verstraete. W. Rabaey. K. Enwiron. Sci. Techol. 2006, 40.5181 .

5. Shin, S.-H; Choi, Y; Na. S.: Jung. S; Kim. S. Bull. Konam Chent Soc. 2006. 27. 281.

6. Reimers. C. E.: Tender. L. M.: Fertig. S.: Wang. W. Eminon. Sci. Techol. 2001.35. 192

7. Bond. D. R.; Holmes. D. E.; Tender L. M.; Lovley, D. R. Science? 2002. $295,483$.

8. Tanaka, K.: Kashiwagi, N.: Ogawa. T. J. Chem. Tech Biotechol. 1988. +2. 235

9. Yagishita. T.: Horigome. T.: Tanaka. K. J. Chent. Tech Biotechnol. 1993. 56.393

10. Choi, Y.: Song, J.: Jung, S.: Kim. S. J. Micobiol Biotechol 2001. 11,863

11. Kim. N, Choi, Y: Jung, S.: Kim, S. Bull. Korean Chem. Soc 2000. 21. 44.

12. Choi. Y.: Kiml. N.: Kiml. S.: Tung. S. Bull. Korem Chem. Soc. 2003. 24. 437

13. Kim. N.: Choi. Y.; Jung. S.; Kim. S. Biotechol. Bioeng, $2000,70$. 109.

14. Choi. Y; Jung, E.; Park, H.; Paik, S. R.: Jung. S.: Kim. S. Bull. Korem Chem. Soc. 2004. 25.813.

15. Madigan. M.: Martinko. T. Brock Biologl of Mficroorganisms. $11^{\text {th }}$ ed.: Prentice Hall: 2005.

16. Bennetto, H. P.: Stirling, J. L.; Tanaka, K. Chem. Ind. (London 1985.695

17. Choi. Y; Jung, J:; Jung. S.: Kim, S. Bioelectrochem 2003, 59. 121. 